Transport and Communications Science Journal

\title{
DESIGN, CONSTRUCTION AND ANALYSIS FOR SUPER-WIDE, DEEP AND LARGE FOUNDATION PIT
}

\author{
Shenjie Shi ${ }^{1}$, Angran Tian ${ }^{1}$, Yongsheng Zheng ${ }^{2}$, \\ Peng Yin ${ }^{2}$, Weilin $\mathbf{Q i}^{3}$, Qiang Tang ${ }^{1,4,5^{*}}$ \\ ${ }^{1}$ School of Rail Transportation, Soochow University, Suzhou, China \\ ${ }^{2}$ China Railway Second Group of The Fourth Engineering Co., Ltd, Suzhou, China \\ ${ }^{3}$ Suzhou Xiangcheng Communications Construction Inves. Group Co.,Ltd, Suzhou, China \\ ${ }^{4}$ Key Laboratory of Ministry of Education for Geomechanics and Embankment Engineering, \\ Hohai University, Nanjing, China \\ ${ }^{5}$ Jiangsu Research Center for Geotechnical Engineering Technology, Hohai University, \\ Nanjing, China
}

\section{ARTICLE INFO}

TYPE: Research Article

Received: 5/10/2020

Revised: 30/10/2020

Accepted: 6/11/2020

Published online: 25/01/2021

https://doi.org/10.47869/tcsj.72.1.13

* Corresponding author

Email: tangqiang@suda.edu.cn

Abstract. Both developing and developed countries are facing a series of difficulties and challenges in the process of urbanization. In recent years, in order to alleviate the problem of urban congestion, underground space has developed rapidly, and the excavation of foundation pit is the most important step in the development of underground space. This paper takes the foundation pit of the tunnel under construction in Suzhou as a research object. The design width of the foundation pit reaches $61.5 \mathrm{~m}$ and the depth reaches $18 \mathrm{~m}$, so it belongs to the super wide and deep foundation pit. Numerical analysis is performed by finite element software to calculate the deformation of the foundation pit. The research shows that the main problem to be solved is the deformation of the foundation pit, and the deformation of side wall of foundation pit tunnel is the most obvious. The maximum deformation of the side wall of the main tunnel and the auxiliary tunnel reached the maximum at $15 \mathrm{~m}$. The maximum deformation of the main tunnel is about $1.3 \mathrm{~cm}$, and that of the auxiliary tunnel is about 0.9 $\mathrm{cm}$. Through targeted design and construction, the mechanical performance of the foundation pit retaining structure is optimized, and the stability of the foundation pit is strengthened. The reasonable retaining structure can ensure the good construction quality. The design and construction of the project can provide reference for related engineering construction.

Keywords: super-wide foundation pit, design and construction, numerical calculation, retaining structure. 


\section{INTRODUCTION}

With the development of urbanization, the contradiction between the increase of urban population and the limited space on the ground is becoming increasingly prominent, and the development of underground space resources is an effective way to solve this contradiction [1-3]. The development of underground space has many advantages. For example, underground space development can save ground space resources and alleviate the problem of urban congestion. In addition, in the process of using underground space construction, the impact on the original ground construction facilities and traffic is very small, which can effectively reduce the pressure of ground transportation [4]. At present, underground engineering, such as underground tunnel, metro and underground pipe gallery, has been constructed and developed in major cities in the world. Underground engineering scale space, the number is also increasing, and the surrounding natural and environmental conditions of the project are becoming more complex [5, 6]. Of course, a considerable part of the construction of underground space is carried out by open-air excavation method, which cannot be separated from foundation pit engineering.

As a complex and comprehensive research subject, foundation pit engineering covers a wide range of contents, including foundation pit support, foundation pit excavation and foundation pit drainage technology [7-9]. Among these, there are mainly four aspects of problems: (1) the assumption of soil constitutive relation and failure of soil stability strength; (2) the problems that the deformation of regional are diversified; (3) some mechanical analysis of foundation pit supporting members is not clear; and (4) the deformation coordination between the structure and the soil in the reinforced members. With the development of mechanical theory, computer technology and testing equipment, the above mentioned problems have gradually been more in-depth and mature research. Many scholars have already studied the deformation and stress of foundation pit for a long time [5]. Lame made a qualitative study on the foundation pit through experiments and obtained the factors influence regional soil deformation, such as, types of excavation soil, sizes of foundation pit excavation, the surrounding environment, the exposure time after excavation, the form of it supporting structure, and static and dynamic load around the foundation pit [6]. Peck derived a theoretical calculation formula by mathematical induction. The formula is about the relationship between the characteristics of foundation pit soil layer and excavation depth, and draws Peck curve $[10,11]$.

Since the 1960s, lots of architectural engineering designs employ the finite element method [12-14]. At first, it is used to analyse structural matrix, and then it is gradually used in various mechanical analysis. After a large number of applications in engineering design, it is found that the finite element method not only has high efficiency, but also has small calculation error [15]. Therefore, it is very popular in various engineering design fields. During several years, the continuous development of computer technology, people continue to develop a variety of finite element analysis software [16-17]. In solving the complex conditions of foundation pit engineering method, the application of numerical analysis software is also quite common. Wong used finite element technique to study the influence of change water level inside and outside foundation pit on excavation construction of foundation pit, and concluded that affect changes the water level inside and outside foundation pit on the deformation of foundation pit is obvious during excavation process of it so the underground water level should be monitored inside and outside the foundation pit at all times during the construction of it [18]. In recent years, finite element software used in foundation pit 
engineering has emerged rapidly. The application of these software promotes the progress of engineering and mechanical design $[19,20]$.

This paper relies on the specific project in Suzhou as the research background, and discusses the design and construction method of super wide foundation pit. The finite element software is also used to analysis the deformation of foundation pit and surrounding soil layer [21-23]. This paper can provide reference for the construction of some deep foundation pit.

\section{INTRODUCTION}

\subsection{Project introduction}

The project is located in Suzhou, China. The tunnels are mainly composed of main tunnel and auxiliary tunnel. The main tunnel is used for motor vehicles, while the auxiliary tunnel is used for non-motor vehicles and pedestrians. The tunnel excavation adopts the method of vertical support and internal support. In the tunnel extension project, the depth of foundation pit excavation reaches $18 \mathrm{~m}$ and the width reaches $61.5 \mathrm{~m}$, which belongs to the excavation of super wide and deep foundation pit. In addition, the environment which is located in the surrounding of the foundation pit is extreme complex, and with the distribution of underground pipelines is densely, and the design and construction are difficult.

\subsection{Engineering geological conditions and hydrogeological conditions}

The soil layer around the foundation pit is shown in Table 1. The upper silt and clay layer have poor water permeability, relatively stable horizon, and belong to relatively impermeable layer with poor water yield. The groundwater is mainly the upper stagnant water in the upper fill, which is mainly affected by farmland irrigation, domestic water, surface runoff, atmospheric precipitation, mountain stream confluence and so on. It is discharged by evaporation and infiltration, and has poor hydraulic connection with the lower groundwater.

Table 1. Physical and mechanical parameters of soil layer in foundation pit area.

\begin{tabular}{lcccc}
\hline \hline & $\begin{array}{c}\text { Thickness of } \\
\text { soil layer }(\mathbf{m})\end{array}$ & $\begin{array}{c}\text { Density } \\
\left(\mathbf{g} / \mathbf{c m}^{\mathbf{3}}\right)\end{array}$ & $\begin{array}{c}\text { Cohesion } \\
(\mathbf{k P a})\end{array}$ & Friction angle $\left(^{\circ}\right)$ \\
\hline Miscellaneous fill & 4.2 & 1.88 & 10 & 8 \\
\hline Silt & 2.2 & 1.89 & 26.8 & 14.5 \\
\hline $\begin{array}{l}\text { Silt mixed with silty } \\
\text { clay }\end{array}$ & 6.9 & 1.75 & 13.5 & 12.3 \\
\hline Clay & 2.5 & 1.95 & 47.4 & 15.7 \\
\hline Silty clay & 2.6 & 1.92 & 34.8 & 16.3 \\
\hline Sandy clay & 5.7 & 1.86 & 7.6 & 24.1 \\
\hline Silt & 7.3 & 1.87 & 2.8 & 14.3 \\
\hline \hline
\end{tabular}

\subsection{Environment around the foundation}

From the beginning to the end of the tunnel, there are farmland and ponds on both sides. The south side of the east section of the tunnel has a residential building, and about $28 \mathrm{~m}$ away from the tunnel foundation pit. The tunnel passes through the planned lake, the planned north extension of Rail Transit and the planned north extension line of pipe gallery. In addition, there are rainwater pipes, power lines, high-voltage power overhead lines, 
communication lines, defence cables and other underground pipelines within the scope of it, which makes the construction of the retaining structure and main structure of foundation pit very difficult.

\subsection{Design of super wide foundation pit}

The main tunnel was close to the auxiliary tunnel, and the foundation pit was wide, reaching $61.5 \mathrm{~m}$. In order to improve the stability and mechanical performance of the foundation pit, the following measures were taken:

(1) The main foundation pit and the auxiliary tunnel were constructed by stages, the main tunnel was constructed first, and then the auxiliary tunnel was constructed. The pit in pit supporting structure formed an effective force transmission system to ensure the stability of the foundation pit.

(2) When the design elevation difference between the main tunnel foundation pit and the auxiliary tunnel foundation pit was more than $3 \mathrm{~m}$, the bored pile was used as the retaining structure between the them. The soil depth is determined according to the elevation difference, geological conditions, surrounding environmental conditions and the calculation results of pit in pit module of relevant software.

(3) In order to ensure the construction convenience and durability of the tunnel connection point, the top ring beam of the high and low pit retaining structure was set under the auxiliary tunnel bottom plate, so that the enclosure and the structure did not affect each other. The construction joints were reduced.

(4) In order to ensure the stability of the high and low pit, the bottom cushion of the tunnel was set as a reinforced concrete structure, which was poured with the top ring beam to ensure that the support force can be effectively transmitted to the enclosure structure, so as to improve the stress condition and stability of the high and low pit retaining structure.

\section{NUMERICAL ANALYSIS}

\subsection{Parameter selection}

Table 2. Support structure parameters.

\begin{tabular}{lccc}
\hline \hline Concrete support & Geometric properties & $\begin{array}{c}\text { Density } \\
\left(\mathbf{g} / \mathbf{c m}^{\mathbf{3}}\right)\end{array}$ & $\begin{array}{c}\text { Elastic modulus } \\
(\mathbf{M P a})\end{array}$ \\
\hline Steel support & $800 \mathrm{~mm} \times 800 \mathrm{~mm}$ & 2.4 & 30000 \\
\hline Bored pile & $\mathrm{D}=600 \mathrm{~mm}$ or $800 \mathrm{~mm}, \mathrm{t}=16 \mathrm{~mm}$ & 7.8 & 2100000 \\
\hline Steel purlin & $\mathrm{D}=800 \mathrm{~mm}$, spacing $1000 \mathrm{~mm}$ & 2.4 & 30000 \\
\hline \hline
\end{tabular}

The parameter selection of soil and other structures can directly affect the calculation results. The parameters needed in the process of finite element numerical calculation include soil parameters and support structure parameters, which is shown in Table 1 and Table 2. The Mohr Coulomb model was adopted for the soil and elastic model was used for supporting structure [24-27]. In order to improve the calculation accuracy, the model width was three times of the foundation pit width, which was $200 \mathrm{~m}$. In order to show the grid division and the 
deformation of soil layer clearly, the following figures only intercepted the area with large deformation around the foundation pit.

\subsection{Modeling and meshing}

After setting the parameters, the geometric model was established according to the shape of foundation pit in practical engineering. The cross section of foundation pit is shown in Figure 1. In order to carry out finite element analysis, the geometric model needed to be meshed., as shown in Figure 2. The displacement of the side and the bottom of the model was limited, and the upper surface was free.

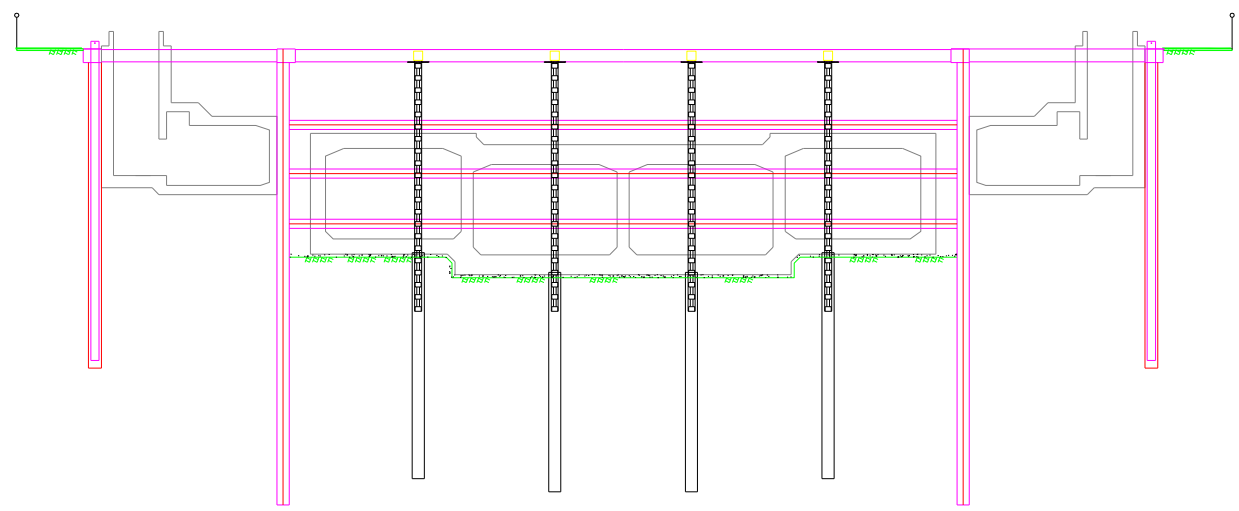

Figure 1. Cross section of foundation pit.

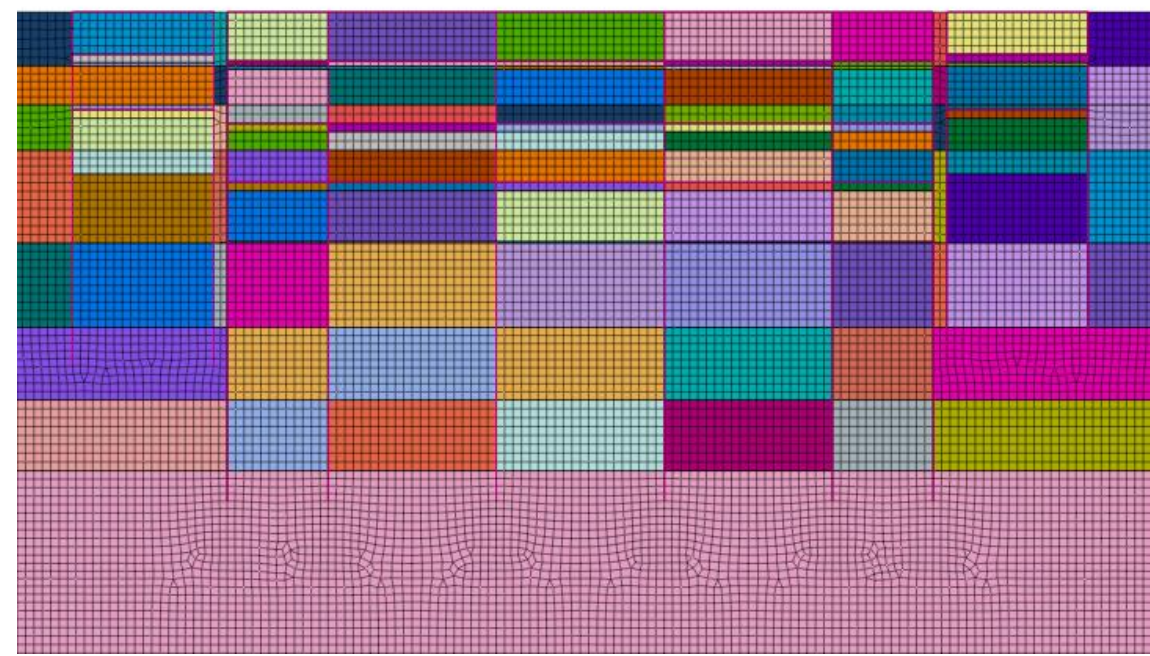

Figure 2. Meshing results.

\subsection{Construction steps}

According to the specific construction steps of the project, the excavation in layers and blocks was adopted. First, the earth stress was balanced to remove the deformation caused by the weight of the soil. The retaining pile and the first internal support were activated for the first excavation. The excavation continued step by step after the internal support was applied until the excavation of the main tunnel was completed. After the excavation of the main tunnel was completed, the excavation of the auxiliary tunnel was carried out.

\subsection{Results and discussion}

After the excavation of the main tunnel, the soil deformation is shown in Figure 3. The maximum deformation was $3 \mathrm{~cm}$, which was the uplift of the foundation pit bottom. Due to 
the large stiffness of retaining pile, the deformation of foundation pit periphery was less than $1 \mathrm{~cm}$.

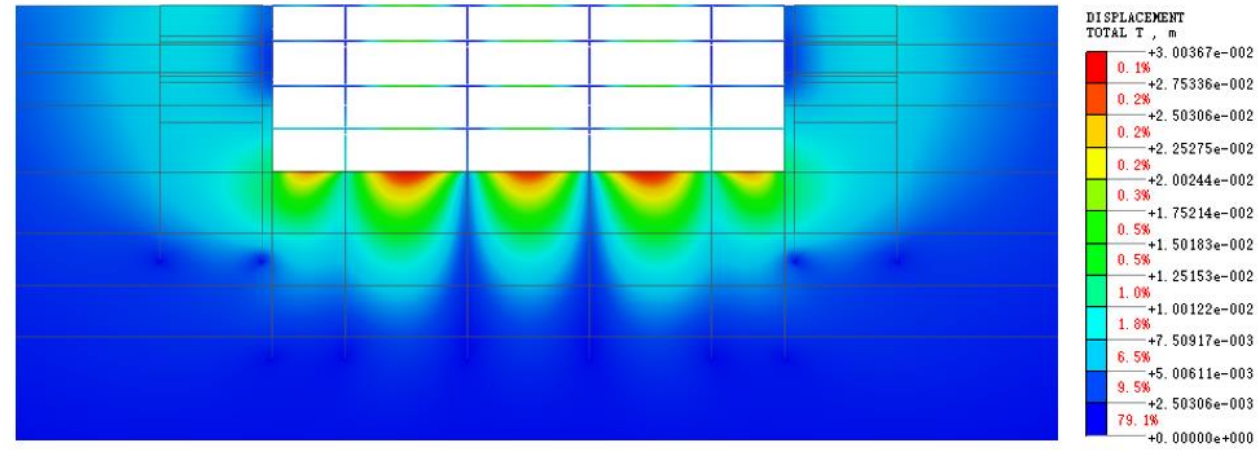

Figure 3. Deformation of foundation pit during excavation of main tunnel.

Foundation pit deformation was mainly manifested by the protuberance at the bottom of the foundation pit, with maximum deformation was about $3 \mathrm{~cm}$ in Figure 4. Due to the role of retaining piles, the excavation of auxiliary tunnel had little impact on the uplift of the foundation pit bottom of the main tunnel. The uplift at the bottom of the foundation pit of the auxiliary tunnel was also controlled within $3 \mathrm{~cm}$. This is consistent with the results of previous studies [28-30].

Due to the stress balance of the soil destroyed by unloading during the excavation process, the rebound deformation would appear, which caused the uplift. However, the serious uplift will cause the instability of foundation pit. Therefore, the bottom of foundation pit needs to be strengthened to prevent accidents.

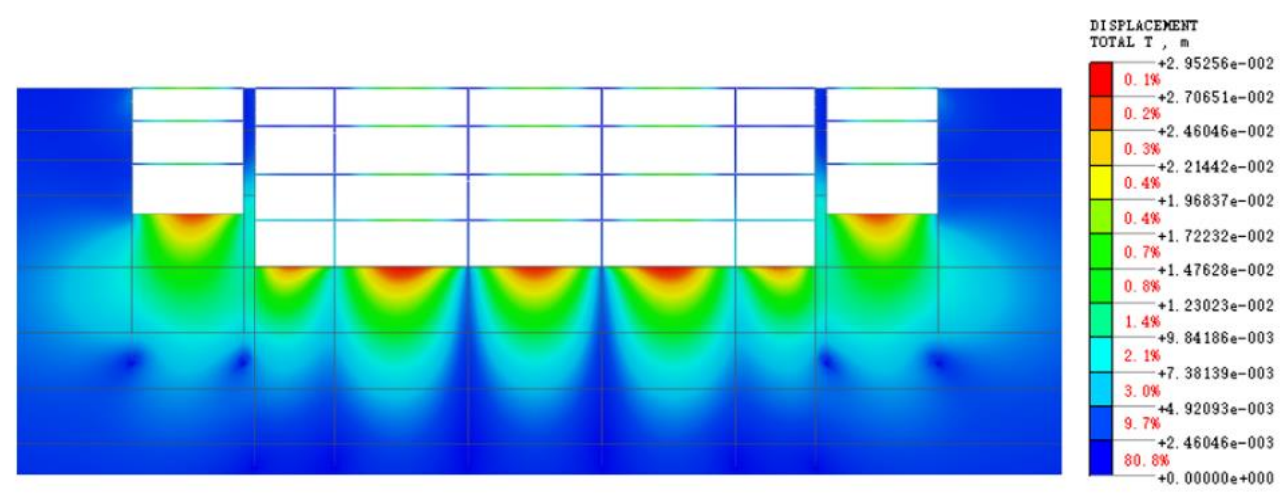

Figure 4. Final deformation of foundation pit.

Through the simulation analysis in Figure 5, the ground deformation was the land subsidence. The maximum settlement occurred at the edge of the foundation pit, about 0.7 $\mathrm{cm}$. With the increase of excavation depth, the deformation gradually increases. However, after the excavation of the auxiliary tunnel, the ground deformation decreases due to the decrease of excavation depth and the release of earth pressure. By comparing the ground deformation near the foundation pit, it can be found that the deformation decreased rapidly with the increase of distance. When the distance was more than $12 \mathrm{~m}$, the influence of excavation was limited, and the deformation was within $0.3 \mathrm{~cm}$. This is consistent with the results of previous research [31-33]. 


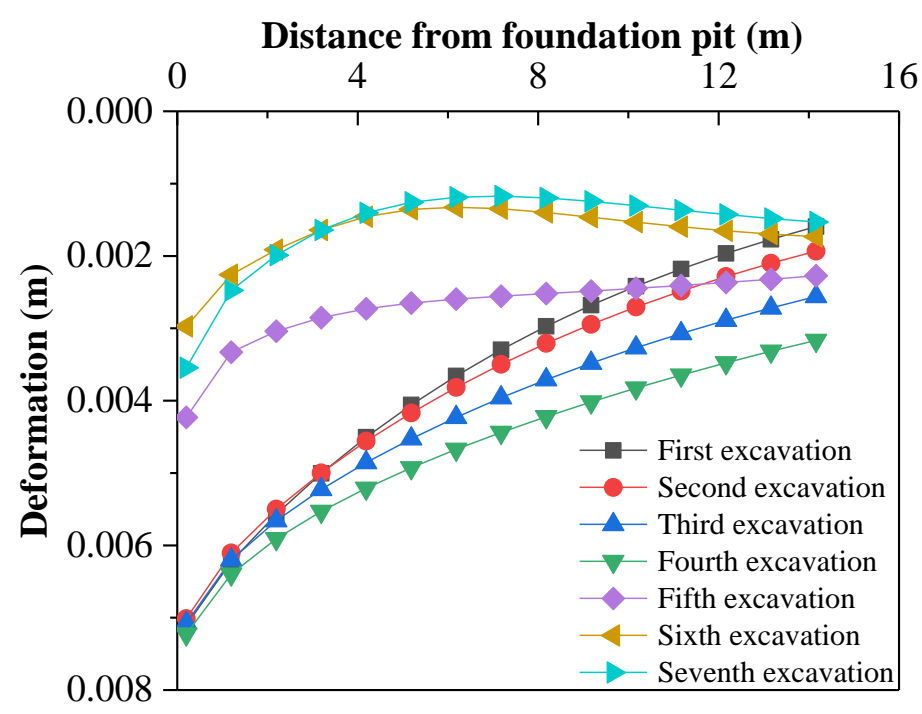

Figure 5. Deformation at different positions from the foundation pit.

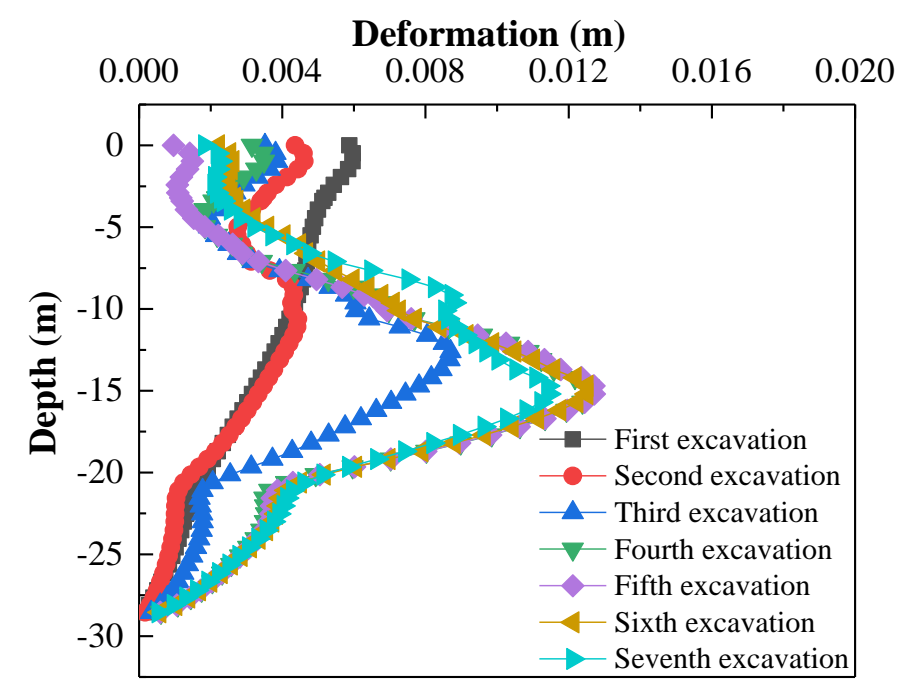

Figure 6. Deformation of the side wall of the main tunnel

In order to understand the deformation of the side wall of many foundation pits, the deformation of side walls of main tunnel and auxiliary tunnel during the construction were calculated [34]. The deformation of the side wall of the main tunnel is shown in Figure 6. The deformation of the side wall was small on the ground and increased with depth. The maximum deformation was $1.3 \mathrm{~cm}$ at the depth of $15 \mathrm{~m}$. During the excavation of the main tunnel, the deformation of the side wall of the main tunnel did not change significantly with the increase of the excavation depth. This is because the internal support counteracted the lateral soil pressure. However, when the auxiliary tunnel was excavated, the deformation of the side wall of the main tunnel increased rapidly. This is due to the fact that during the excavation of the auxiliary tunnel, the lateral earth pressure was transferred to the side wall of the main tunnel through the inner support of the auxiliary tunnel, and the form of the earth pressure changed from distributed force to concentrated force. This shows that it is necessary to strengthen the monitoring work during the excavation of the auxiliary tunnel. In addition, prestressed internal support or servo system can be used to adjust the axial force of the support in the main tunnel to reduce the deformation [35-37].

The deformation of the side wall of the auxiliary tunnel is shown in Figure 7. During the 
excavation of the main tunnel, the deformation of the side wall of the auxiliary tunnel increased with the increase of the excavation depth, but it did not exceed $0.7 \mathrm{~cm}$. When the auxiliary tunnel was excavated, the deformation of the side wall of the auxiliary tunnel changed greatly. At this time, the deformation of the auxiliary tunnel was caused by the lateral earth pressure and the supporting axial force, so it presented S-shape. The reason for the sudden change is because of the supporting axial force. This is consistent with previous studies [38]. The maximum deformation is $0.9 \mathrm{~cm}$ at the depth of $15 \mathrm{~m}$. The excavation depth of the auxiliary tunnel was at $15 \mathrm{~m}$, and the bending moment reached the maximum at the bottom of the foundation pit. The lower soil layer had a strong lateral pressure on the retaining pile, which reduced the bending moment and limited the deformation of the side wall, thus the deformation decreases rapidly. This also shows that increasing the stiffness of the retaining structure and internal support and reducing the spacing of the internal supports can reduce the deformation of the side wall of the foundation pit.

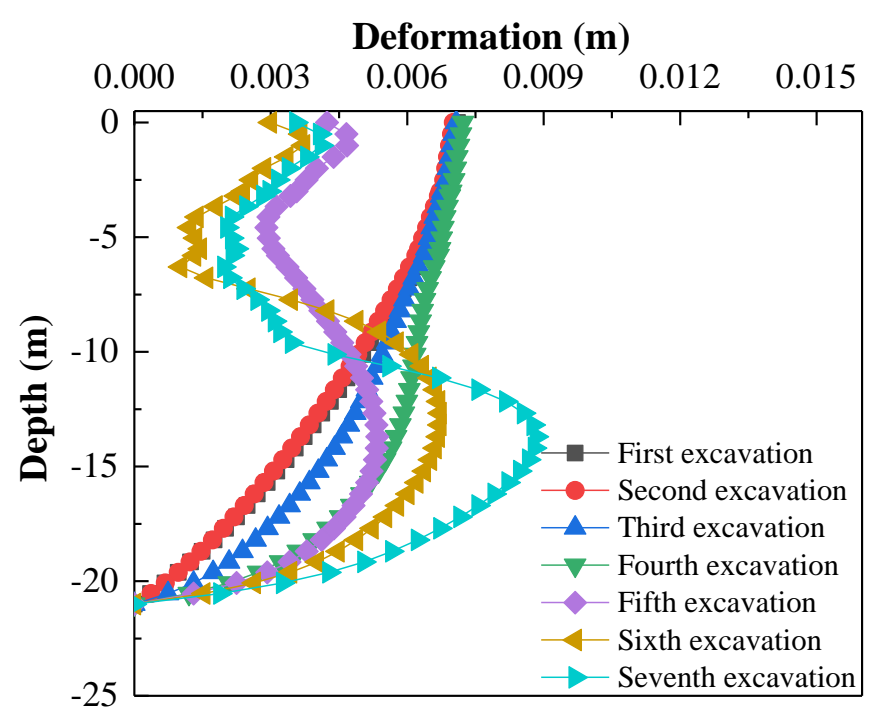

Figure 7. Deformation of the side wall of the auxiliary tunnel.

\section{CONCLUSION}

Based on the case study of a super wide, deep and large tunnel foundation pit in Suzhou, this paper mainly draws the following conclusions:

(1) In the process of foundation pit excavation, the maximum deformation mainly occurred at the bottom of foundation pit, which was $1.3 \mathrm{~cm}$.

(2) With the increase of the distance from the foundation pit, the ground deformation became smaller. When the distance was $12 \mathrm{~m}$, the deformation was nearly stable, which was $0.3 \mathrm{~cm}$

(3) The maximum deformation of the main tunnel and the auxiliary tunnel occurred at the depth of $15 \mathrm{~m}, 1.3 \mathrm{~cm}$ and $0.9 \mathrm{~cm}$, respectively.

(4) The deformation of the side wall of the foundation pit can be effectively reduced by reasonably arranging the construction sequence and supporting structure.

\section{ACKNOWLEDGMENT}

The research presented here is supported by the National Nature Science Foundation of China (52078317), Natural Science Foundation of Jiangsu Province (BK20170339), project from Jiangsu 
Transport and Communications Science Journal, Vol. 72, Issue 1 (01/2021), 117-126

Provincial Department of Housing and Urban-Rural Development (2020ZD05), and Bureau of Housing and Urban-Rural Development of Suzhou (2019-14, 2020-15).

\section{REFERENCES}

[1]. F. Yang et al., Research on Deep Foundation Pit Excavation Based on Data Monitoring, IOP Conference Series Earth and Environmental, 525 (2020) 12-14. http://doi.org/10.1088/1755$\underline{1315 / 525 / 1 / 012014}$

[2]. Y. Qiu et al., Surface characteristics of crop-residue-derived black carbon and lead(II) adsorption, Water Research, 42 (2008) 567-574. http://doi.org/10.1016/j.watres.2007.07.051

[3]. Q. Zhang, Deformation Analysis of Deep Foundation Pit Excavation Under the Effect of Time and Space, Geotechnical Research, 7 (2020), 146-152.https://doi.org/10.1680/jgere.20.00009

[4]. L. Jinjun et al., Monitoring and Analysis of Foundation Pit Excavation of City Open-cut Tunnel, International Conference on Computing, IEEE Computer Society, 2012.

[5]. W. X-Jun, Participatory geographic information system review, Chinese Journal of EcoAgriculture, 18 (2010) 1138-1144 .https://doi.org/10.3724/SP.J.1011.2010.01138

[6]. Z-bin. Fu et al., Construction of Foundation Pit without Dewatering, Geo-Shanghai, 2014. https://doi/org/ 10.1061/9780784413449.089

[7]. Y. Tan, D. Wang, Characteristics of a Large-Scale Deep Foundation Pit Excavated by the Central-Island Technique in Shanghai Soft Clay, II: Top-Down Construction of the Peripheral Rectangular Pit, Journal of geotechnical and geo-environmental engineering, 139 (2013) 1894-1910. https://doi.org/10.1061/(ASCE)GT.1943-5606.0000929

[8]. Y. Li et al., Deformation Behavior of Foundation Pit Considering the Variation of Permeability Coefficient of Soil Mass, 2018. https://doi.org/10.1007/978-981-13-0131-5_41

[9]. X. Zhang et al., Deformation Response of an Existing Tunnel to Upper Excavation of Foundation Pit and Associated Dewatering, International Journal of Geo-mechanics, 17 (2017) 1-14. http://doi.org/10.1061/(ASCE)GM.1943-5622.0000814

[10]. X. Y. Xie, K. W. Zhu, Development of a Three-Dimensional Modeling Method for Monitoring Overall Foundation Pit Deformation Based on Terrestrial Laser Scanning, Applied Mechanics and Materials, 743 (2015) 866-875. https://doi.org/10.4028/www.scientific.net/AMM.743.866

[11]. R.P. Peek, Deep Excavations and Tuneling in Soft Ground, Proc. of 7th ICSMFE, Mexico, (1969).

[12]. X. Wang et al., Preparation of Macroporous $\mathrm{Al}_{2} \mathrm{O}_{3}$ by Template Method, Acta Physico-Chimica Sinica, 22 (2006) 831-835. http://doi.org/10.1016/S1872-1508(06)60035-1

[13]. W. X-Jun, The Influence of foundation pit excavation on adjacent metro deformation, Chinese Journal of Eco-Agriculture, 18 (2010) 1138-1144. http://doi.org/10.3724/SP.J.1011.2010.01138

[14]. T. Wortmann et al., Advantages of surrogate models for architectural design optimization, Ai Edam Artificial Intelligence for Engineering Design Analysis \& Manufacturing, 29 (2015) 471-481. http://doi.org/10.1017/S0890060415000451

[15]. Y. Tan et al., Zoned Excavation of an Oversized Pit Close to an Existing Metro Line in Stiff Clay: Case Study, Journal of Performance of Constructed Facilities, 29 (2015) 1-19. http://doi.org/10.1061/(ASCE)CF.1943-5509.0000652

[16]. H. Liu et al., The Finite Element Analysis of Pile-Anchor Support System in Foundation Pit, 2009 Second International Conference on Information and Computing Science, 2009, pp. 131-134. http://doi.org/10.1109/ICIC.2009.40

[17]. F. Naghibi et al., Probabilistic considerations for the design of deep foundations against excessive differential settlement, Canadian Geotechnical Journal, 53 (2016). http://doi.org/10.1139/cgj-2015-0194

[18]. Y. Fei, Influence of groundwater on stability of excavation foundation pit based on finite element analysis, Journal of University of Science and Technology Liaoning, (2015).

[19]. K. S. Wong, B. B. Broms, Lateral Wall Deflection of Braced Excavation in Clay, Journal of the 
Transport and Communications Science Journal, Vol. 72, Issue 1 (01/2021), 117-126

Geotechnial Engineering, 115 (1989). http://doi.org/10.1061/(ASCE)0733-9410(1989)115:6(853)

[20]. C. Mahrenholtz, R. Eligehausen, Simulation of Tests on Cast-In and Postinstalled Column-toFoundation Connections to Quantify the Effect of Cyclic Loading, Journal of Structural Engineering, 142 (2016), 1-10. http://doi.org/10.1061/(ASCE)ST.1943-541X.0001330

[21]. J. Wei et al., The Finite Element Analysis of Highway Unilateral Widened Deformation Characteristics on Soft Soil Ground, Advanced Science Letters, 6 (2012) 337-341. http://doi.org/10.1166/asl.2012.2257

[22]. J. Zhang, Finite Element Analysis of Ultra-deep Foundation Pit Covered Top-Down Excavation Based on PLAXIS, IOP Conference Series: Earth and Environmental Science, 300 (2019) 022158. http://doi.org/10.1088/1755-1315/300/2/022158

[23]. D'A. Hayman, Unesco Symposium on Technology and Artistic Creation in the Contemporary World, JOURNAL ARTICLE, 1 (1968) 441-444. http://doi.org/10.2307/1571996

[24]. Y. L. Lin et al., Experimental and numerical study on the seismic behavior of anchoring frame beam supporting soil slope on rock mass, Soil Dynamics and Earthquake Engineering, 98 (2017), 1223. http://doi.org/10.1016/j.soildyn.2017.04.008

[25]. C. W. Boon, G.T. Houlsby, S. Utili, Designing Tunnel Support in Jointed Rock Masses Via the DEM. Rock Mechanics \& Rock Engineering, 48(2015) 603-632. https://doi.org/10.1007/s00603-014$\underline{0579-8}$

[26]. Pankaj, N. Bicanic, Detection of Multiple Active Yield Conditions for Mohr-Coulomb Plasticity, Computers and Structures, 62 (1997) 51-61. https://doi.org/10.1016/S0045-7949(96)00267-2

[27]. S. Sysala et al., Sub-differential based implicit return-mapping operators in Mohr-Coulomb plasticity, Journal of Applied Mathematics \& Mechanics, 2017.http://doi.org/10.1002/zamm.201600215 [28]. X. Shi et al., Analysis on Deformation and Stress Characteristics of a Multi-braced Pit-in-Pit Excavation in a Subway Transfer Station, Advances in Civil Engineering, 10 (2020) 1-19. http://doi.org/10.1155/2020/8844461

[29]. I. Sabirov et al., Nanostructured a luminium alloys produced by severe plastic deformation: New horizons in development, Materials Science \& Engineering: A, 560 (2013) 1-24. http://doi.org/10.1016/j.msea.2012.09.020

[30]. Z. Chang et al., Effects of the Loading and Unloading Conditions on Crack Propagation in High Composite Slope of Deep Open-Pit Mine, Advances in Civil Engineering, 6 (2019) 11. http://doi.org/10.1155/2019/3168481

[31]. N. Liosis et al., Ground subsidence monitoring with SAR interferometry techniques in the rural area of Al Wagan, UAE, Remote Sensing of Environment, 216 (2018) 276-288. http://doi.org/10.1016/j.rse.2018.07.001

[32]. T. H. Phi, L. A. Strokova, Prediction maps of land subsidence caused by groundwater exploitation in Hanoi, Vietnam, Resource-Efficient Technologies, 1 (2015) 80-89. http://doi.org/10.1016/j.reffit.2015.09.001

[33]. A. M. Suchowerska et al., Geo-mechanics of subsidence above single and multi-seam coal mining, Journal of Rock Mechanics and Geotechnical Engineering, 8 (2016) 304-313. https://doi.org/10.1016/j.jrmge.2015.11.007

[34]. C. Qi et al., Deformation and Stability of Soft Foundation Improved by Prefabricated Vertical Drains Adjacent to River Bank, Advances in Civil Engineering, 10 (2018) 1-7. https://doi.org/10.1155/2018/2948286

[35]. Y. Li et al., Deformation and mechanical characteristics of tunnel lining in tunnel intersection between subway station tunnel and construction tunnel, Tunnel and Underground Space Technology, 56 (2016) 22-33. https://doi.org/10.1016/j.tust.2016.02.016

[36]. H. Zhang et al., A new model to predict soil pressure acting on deep burial jacked pipes, Tunnel and Underground Space Technology, 60 (2016) 183-196. https://doi.org/10.1016/j.tust.2016.09.005

[37]. J. P. Doherty, A numerical study into factors affecting stress and pore pressure in free draining mine stopes, Computers \& Geotechnics, 63 (2015) 331-341. https://doi.org/10.1016/j.compgeo.2014.10.001

[38]. M. Patil et al., Behavior of shallow tunnel in soft soil under seismic conditions, Tunnel and Underground Space Technology, 82 (2018) 30-38. https://doi.org/10.1016/j.tust.2018.04.040 